\title{
Prevalence of gastro-oesophageal reflux disease symptoms and reflux-associated respiratory symptoms in asthma
}

\author{
Lakmali D Amarasiri ${ }^{1 *}$, Arunasalam Pathmeswaran ${ }^{2 \dagger}, \mathrm{H}$ Janaka de Silva ${ }^{3 \dagger}$, Channa D Ranasinha ${ }^{4 \dagger}$
}

\begin{abstract}
Background: Gastro-oesophageal reflux disease (GORD) symptoms are common in asthma and have been extensively studied, but less so in the Asian continent. Reflux-associated respiratory symptoms (RARS) have, in contrast, been little-studied globally. We report the prevalence of GORD symptoms and RARS in adult asthmatics, and their association with asthma severity and medication use.

Methods: A cross-sectional analytical study. A validated interviewer-administered GORD scale was used to assess frequency and severity of seven GORD symptoms. Subjects were consecutive asthmatics attending medical clinics. Controls were matched subjects without respiratory symptoms.

Results: The mean (SD) composite GORD symptom score of asthmatics was significantly higher than controls (21.8 (17.2) versus 12.0 (7.6); $P<0.001)$ as was frequency of each symptom and RARS. Prevalence of GORD symptoms in asthmatics was $59.4 \%$ (95\% Cl, 59.1\%-59.6\%) versus $28.5 \%$ in controls (95\% Cl, $29.0 \%-29.4 \%) .36 \%$ of asthmatics experienced respiratory symptoms in association with both typical and atypical GORD symptoms, compared to $10 \%$ of controls $(P<0.001)$. An asthmatic had a 3.5 times higher risk of experiencing a GORD symptom after adjusting for confounders (OR 3.5; 95\% Cl 2.5-5.3). Severity of asthma had a strong dose-response relationship with GORD symptoms. Asthma medication use did not significantly influence the presence of GORD symptoms.

Conclusions: GORD symptoms and RARS were more prevalent in a cohort of Sri Lankan adult asthmatics compared to non-asthmatics. Increased prevalence of RARS is associated with both typical and atypical symptoms of GORD. Asthma disease and its severity, but not asthma medication, appear to influence presence of GORD symptoms.
\end{abstract}

\section{Background}

Gastro-oesophageal reflux disease (GORD) symptoms are common in asthmatics. A recent systematic review on GORD symptom assessment in asthmatics reported an estimated prevalence ranging from $30-90 \%$ compared to $10-20 \%$ in the general population [1]. A study from South East Asia reported a GORD symptom prevalence of $57 \%$ in asthmatics compared to $34 \%$ in nonasthmatic controls [2], and a study of an urban Indian population found that $74.8 \%$ of asthmatics had a history of GORD [3]. There is also evidence that the

\footnotetext{
* Correspondence: lakmaliamarasiri@gmail.com

+ Contributed equally

'Department of Physiology, Faculty of Medicine, University of Kelaniya,

Ragama, Sri Lanka

Full list of author information is available at the end of the article
}

severity and frequency of GORD symptoms are related to the severity of asthma [4-6]. Individual asthma drugs have also been shown to predispose towards GORD [7-11]. In addition to a higher prevalence of GORD symptoms, asthmatics also associate GORD symptoms with respiratory symptoms, the so-called Reflux Associated Respiratory Symptoms (RARS). Several studies report chronic respiratory manifestations of GORD [12-14]. Others report an association between reflux and cough $[15,16]$ and reflux and bronchial hyperresponsiveness [17-19]. However few studies have investigated whether asthmatics experience respiratory symptoms at the time of GORD symptoms $[20,21]$ and none from the Asian continent.

In this study, we investigated the prevalence of GORD symptoms and RARS in a population of adult asthmatics 
attending a teaching hospital in Sri Lanka, and the association of asthma severity and asthma medication use with the presence of GORD symptoms.

\section{Methods}

A cross-sectional analytical survey was carried out prospectively at the Colombo North Teaching hospital in Sri Lanka over a two year period. Ethical approval was obtained from the Scientific and Ethics Review Committee of the Faculty of Medicine, University of Kelaniya. Adult asthmatics and matched non-asthmatics between the ages of 15-60 years were recruited from medical clinics in the hospital. Those who had previous oesophageal or gastric disease other than GORD, had undergone previous upper gastro-intestinal surgery or had known diabetes mellitus were excluded. All subjects gave informed written consent before the study.

Consecutive asthmatics either newly diagnosed or in follow-up, were recruited according to American Thoracic Society guidelines for the definition of asthma [22]. Controls were either clinic attendees, those accompanying them or hospital staff who did not have respiratory symptoms, asthma or other respiratory illness.

\section{Study protocol}

\section{Diagnosis of asthma}

Subjects were asked five questions to assess presence or absence of asthma symptoms, in relation to a recall period of 12 months preceding the interview [23].

(1) Have you at any time had wheezing or whistling in your chest?

(2) Have you at any time been breathless when you had wheezing or whistling in your chest?

(3) Have you at any time been woken up with a feeling of tightness in your chest?

(4) Have you at any time been woken up by an attack of coughing?

(5) Have you at any time been woken up by an attack of shortness of breath?

Those with a positive response to one or more questions underwent a white cell and differential count examination and a plain chest radiograph. In those with absolute eosinophilia, the Wuchereria bancrofti antigen test $\left(\mathrm{NOW}^{\bullet}\right.$ Filariasis, rapid ICT, Binax, Scarborough, USA) and examination of stools for helminth ova using the direct smear method [24] were done to exclude alternative diagnoses (tropical pulmonary eosinophilia, Loeffler's syndrome). Spirometry was performed using a portable hand-held spirometer (Micro Plus spirometer, Micro Medical Limited, Rochester, UK). Forced Vital Capacity (FVC), Forced Expired Volume in the first second $\left(\mathrm{FEV}_{1}\right)$, Peak Expiratory Flow Rate (PEFR) were recorded after each of three consecutive forced expiratory efforts, both pre and post bronchodilator administration (15 minutes after inhalation of $400 \mu \mathrm{g}$ of salbutamol from a metered dose inhaler via a valved spacer). A $12 \%$ improvement and $200 \mathrm{~mL}$ increase in $\mathrm{FEV}_{1}$ following bronchodilator administration was considered diagnostic of asthma. Predicted values for Sri Lankans were derived from data of Udupihille et al. [25]. Body mass index (BMI) was calculated for each subject.

\section{Assessment of GORD symptoms}

All asthmatics and controls were interviewed by the same investigator using a previously validated GORD scale that assessed the frequency and severity of seven symptoms of reflux disease (table 1) using a recall period of the past 4 weeks. For each symptom the patient was asked two questions: "how often do you have this problem?" to assess frequency, and "how much does this problem bother you?" to assess severity. The frequency and severity were scored on a Likert scale (table 1). The subjects were given a cue card from which they chose the relevant response. A composite symptom score was calculated as the sum of products of symptom frequency and severity of each symptom. This resulted in scores from 1 to 20 for each symptom, with a total maximum score of 140 and a minimum score of 7 . A subject was categorized as GORD symptom positive if the composite

Table 1 Wording of description of gastro-oesophageal reflux disease (GORD) symptoms

\begin{tabular}{ll}
\hline Symptom* & Description \\
\hline $\begin{array}{l}\text { Heartburn } \\
\text { Regurgitation }\end{array}$ & $\begin{array}{l}\text { Burning pain in chest or abdomen } \\
\text { Episodes of bitter or sour fluid or food coming back } \\
\text { to your mouth }\end{array}$ \\
$\begin{array}{l}\text { Abdominal/ } \\
\text { Chest pain }\end{array}$ & $\begin{array}{l}\text { burning pain in the chest or abdomen } \\
\text { Abdominal } \\
\text { distension }\end{array}$ \\
$\begin{array}{l}\text { Feeling of fullness in your upper abdomen } \\
\text { Coughagia }\end{array}$ & $\begin{array}{l}\text { Difficulty in swallowing } \\
\text { Episodes of cough during the day following a meal }\end{array}$ \\
Belching & or at night or when you wake up \\
\hline
\end{tabular}

*Each symptom was asked in relation to meals using a 5-point Likert scale for frequency and a 4-point Likert scale for severity.

e.g. for heartburn.

Do you have any episodes of burning pain in the chest or abdomen?

1 no.

2 once a month.

3 two to three times a week.

4 once a week.

5 daily.

How much does this problem bother you?

1 not at all.

2 mild discomfort, yet does not interfere with day-to-day activities.

3 moderate discomfort, interferes with day-to-day activities at least once a week.

4 severe discomfort, interferes with day-to-day activities and sleep more than once a week. 
GORD score cut-off $\geq$ was 12.5 and as GORD symptom negative if the cut-off was $<12.5$. A subject categorized as GORD symptom negative experienced either infrequent or no symptoms [26].

\section{Assessment of reflux-associated respiratory symptoms}

The presence or absence of cough, shortness of breath, wheeze, and use of reliever medication at the time of experiencing each of the seven GORD symptoms was recorded (table 2).

Further questions were also included on smoking and alcohol habit (whether they were current or past users or had never used), on current asthma medication and duration of use. They were specifically asked whether they were taking oral salbutamol, inhaled salbutamol, oral theophylline, oral steroids and inhaled steroids as these drugs are known to induce GOR.

Table 2 Presence of reflux-associated respiratory symptoms

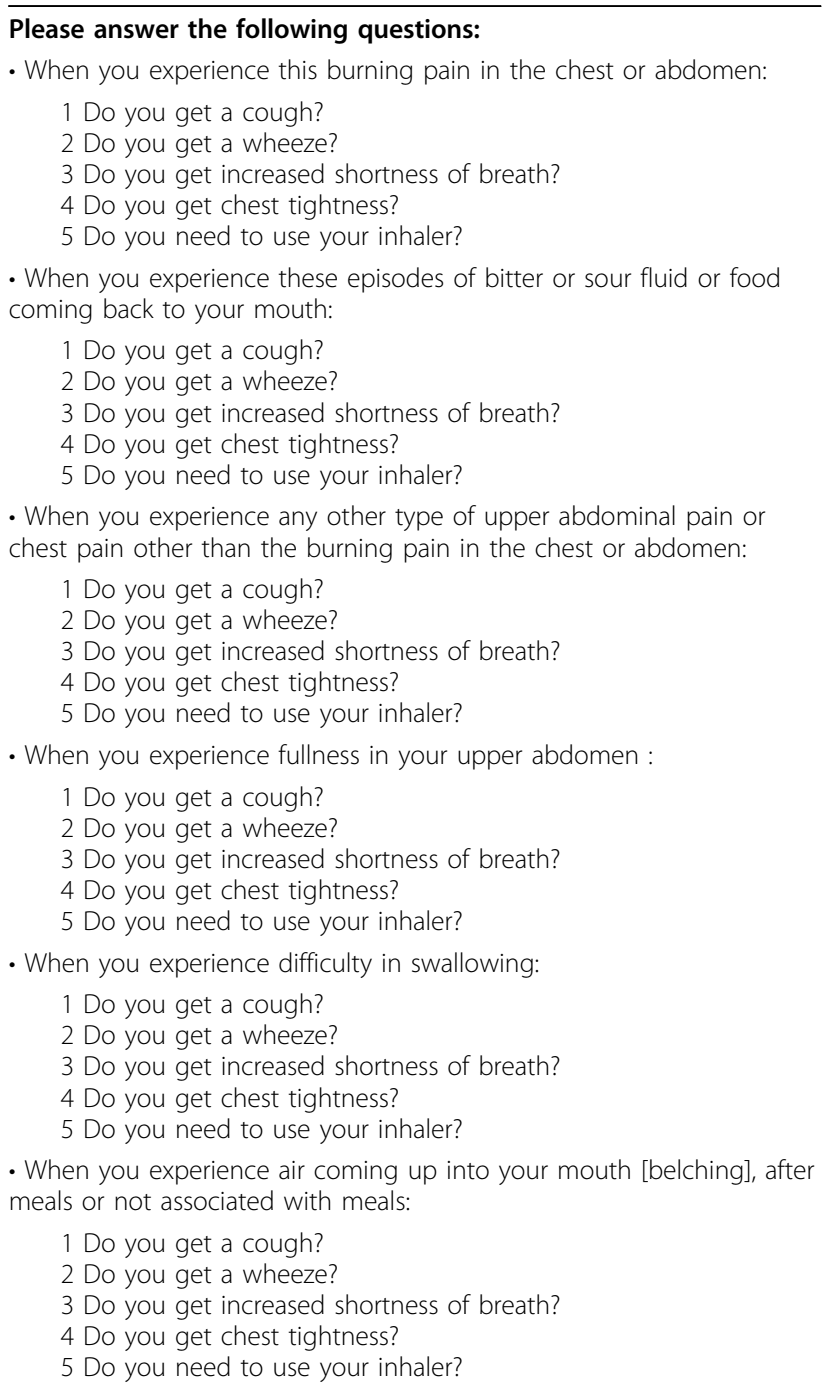

\section{Statistical analysis}

Sample size estimates were made using EpiInfo (EpiInfo 6, version 6.04 (1996), Centres of Disease Control and Prevention, Atlanta, Georgia, USA and World Health Organization, Geneva, Switzerland) and other statistical analyses by SPSS for Windows (version 10, SPSS Inc., Chicago, Illinois, USA). Descriptive statistics are reported as mean and SD. Differences between groups were compared by the student t-test. Association between categorical variables was tested using Fisher Exact Test. Symptom prevalence between asthma and control groups was compared using Pearson Chi Square test. $P$ values of less than 0.05 were considered significant. Cross sectional associations between GORD symptom status and whether asthmatic or not was analyzed by logistic regression analysis where GORD symptom status served as the dependent variable. Analysis was adjusted for known confounders, namely age (categorized into 10 year intervals), gender, BMI (categorized as $<25 \mathrm{~kg} / \mathrm{m}^{2}$ and $\geq 25 \mathrm{~kg} / \mathrm{m}^{2}$ ), smoking (categorized as never smoked or ever smoked) and alcohol habits (categorized as never drank or ever drank). In the asthmatic population, logistic regression was used to examine the relationship between asthma severity and presence of GORD symptoms. The analysis was adjusted for the known confounders and also for types of asthma medication whose use was found to be significantly associated with GORD symptoms on univariate analysis. Odds ratios (OR) and $95 \%$ confidence intervals $(95 \% \mathrm{CI})$ are reported for all logistic regression analyses.

\section{Results}

Two hundred and two asthmatics and 202 controls completed the study. They were comparable in age and sex. Demographic data of the subjects is given in tables 3 and 4 .

\section{Prevalence of GOR symptoms}

The mean (SD) composite GORD score of asthmatics was significantly higher than that of controls (21.8 (17.2) versus 12.0 (7.6); $P<0.001$ Mann Whitney $U$ test). The frequency distribution of each symptom was found to be higher in asthmatics compared to controls (Figure 1).

Table 3 Demographic variables of subjects

\begin{tabular}{lccc}
\hline & $\begin{array}{c}\text { Control } \\
(\boldsymbol{n}=\mathbf{2 0 2})\end{array}$ & $\begin{array}{c}\text { Asthmatic } \\
(\boldsymbol{n}=\mathbf{2 0 2})\end{array}$ & $\boldsymbol{P}$ value \\
\hline Age, yrs mean (SD) & $32.8(10.2)$ & $34.9(11.6)$ & $0.057^{*}$ \\
\hline Males, no (\%) & $86(44 \%)$ & $89(44 \%)$ & $0.841^{\dagger}$ \\
\hline BMl, kg/m² mean (SD) & $22.8(2.84)$ & $22.1(3.03)$ & $0.020^{*}$ \\
Current smokers (\%) & 3.4 & 12.4 & $0.001^{\ddagger}$ \\
Current drinkers (\%) & 7.9 & 14.8 & $<0.001^{\ddagger}$ \\
\hline
\end{tabular}

${ }^{*}$ student t-test ${ }^{\dagger}$ Fisher exact test ${ }^{\ddagger}$ Chi squared test. 
Table 4 Demographic details of asthma patients

\begin{tabular}{|c|c|c|c|}
\hline & $\begin{array}{c}\text { Asthmatics with GORD score } \\
>12.5(n=120)\end{array}$ & $\begin{array}{c}\text { Asthmatics with GORD score } \\
<12.5(n=82)\end{array}$ & $P$ value \\
\hline Age, yrs; mean (SD) & $34.4(11.4)$ & $35.6(11.8)$ & 0.318 \\
\hline Males/females & $53 / 67$ & $36 / 46$ & 1.000 \\
\hline BMl, kg/m²; mean (SD) & $21.9(3.3)$ & $22.6(2.5)$ & 0.126 \\
\hline Current smoker (\% of subjects) & 13.3 & 11.0 & 0.630 \\
\hline Current drinker (\% of subjects) & 20.0 & 7.3 & $0.040^{*}$ \\
\hline \multicolumn{4}{|l|}{ Asthma severity (\% of subjects) } \\
\hline Mild intermittent & 66.7 & 89.0 & 0.001 \\
\hline Mild persistent & 22.5 & 9.8 & \\
\hline Moderate or severe persistent & 10.8 & 1.2 & \\
\hline \multicolumn{4}{|l|}{ Asthma medication (\% of subjects) } \\
\hline Oral salbutamol & 68.3 & 50.0 & $0.009^{*}$ \\
\hline Inhaled salbutamol & 53.3 & 62.2 & 0.212 \\
\hline Oral theophylline & 33.3 & 28.0 & 0.426 \\
\hline Oral steroids & 18.3 & 9.8 & 0.092 \\
\hline Inhaled steroids & 40.0 & 34.1 & 0.399 \\
\hline
\end{tabular}

${ }^{*}$ Chi squared test

Using a cut-off of $>12.5$, the prevalence of symptomatic GORD in asthmatics was significantly higher than that of the controls $(59.4 \%$ [95\% CI, 59.1\%-59.6\%] versus 28.5\% [95\% CI, 29.0\% - 29.4\%]; $P<0.001$ ).

Associations between asthma and GORD symptom status Asthmatics had a higher risk of being GORD symptom positive (score of $>12.5)(\mathrm{OR}, 3.5$ [95\% CI, 2.5-5.3]) and this association remained after adjustment for known confounders, namely age, gender, body mass index (BMI), alcohol and smoking status (OR, 3.7 [95\% CI, 2.4 - 5.8]).

Reflux-associated respiratory symptoms (RARS)

The total number of RARS was higher in asthmatics compared to non-asthmatics with GORD symptom scores $>12.5$ (80\% versus $20 \%, P<0.05$, z test) and also

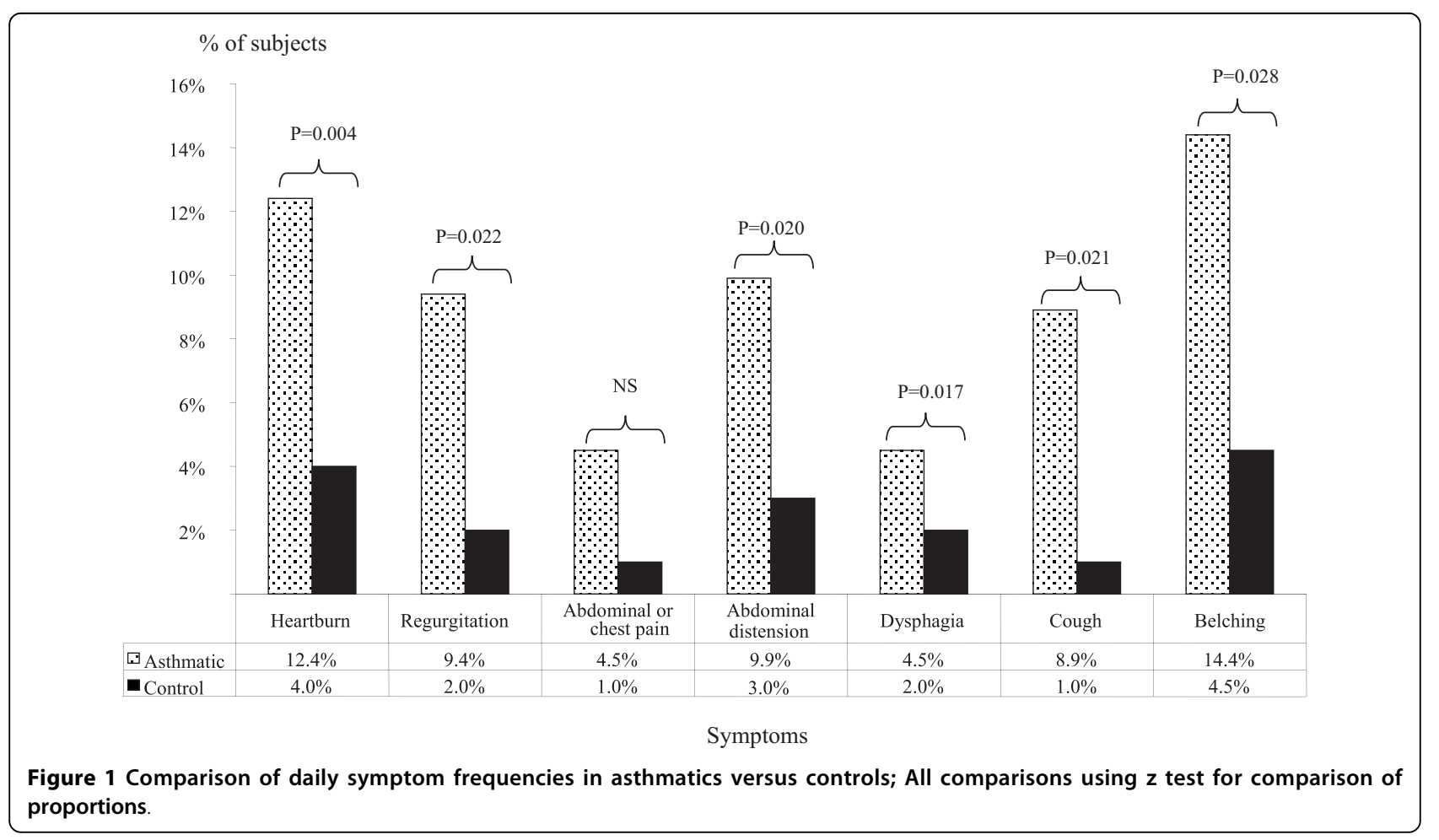


Table 5 Frequency distribution of individual RefluxAssociated Respiratory Symptoms (RARS) in subjects \begin{tabular}{ccc}
\hline RARS & Asthmatics with GORD & Asthmatics with GORD \\
score & score \\
& $>12.5(n=120)$ & $<12.5(n=82)$
\end{tabular}

\begin{tabular}{|c|c|c|}
\hline \multicolumn{3}{|l|}{ Heartburn associated } \\
\hline cough & $3(2.5)$ & $1(1.2)$ \\
\hline wheeze & $4(3.3)$ & - \\
\hline $\begin{array}{l}\text { difficulty in } \\
\text { breathing }\end{array}$ & $50(41.7)$ & - \\
\hline chest tightness & $4(3.3)$ & - \\
\hline inhaler use & $1(0.8)$ & - \\
\hline \multicolumn{3}{|c|}{ Regurgitation associated } \\
\hline cough & $2(1.7)$ & $1(1.2)$ \\
\hline wheeze & $7(5.8)$ & - \\
\hline $\begin{array}{l}\text { difficulty in } \\
\text { breathing }\end{array}$ & $29(24.2)$ & - \\
\hline chest tightness & $2(1.7)$ & - \\
\hline inhaler use & $3(2.5)$ & - \\
\hline \multicolumn{3}{|c|}{ Abdominal/chest pain associated } \\
\hline cough & $2(1.7)$ & - \\
\hline wheeze & $2(1.7)$ & - \\
\hline $\begin{array}{l}\text { difficulty in } \\
\text { breathing }\end{array}$ & $20(16.7)$ & $1(1.2)$ \\
\hline chest tightness & $7(5.8)$ & - \\
\hline inhaler use & $2(1.7)$ & - \\
\hline \multicolumn{3}{|c|}{ Abdominal distension associated } \\
\hline cough & $1(0.8)$ & - \\
\hline wheeze & $3(2.5)$ & $1(1.2)$ \\
\hline $\begin{array}{l}\text { difficulty in } \\
\text { breathing }\end{array}$ & $16(13.3)$ & $2(2.4)$ \\
\hline chest tightness & $7(5.8)$ & - \\
\hline inhaler use & $3(2.5)$ & $1(1.2)$ \\
\hline
\end{tabular}

Dysphagia associated

cough $1(0.8)$

wheeze

difficulty in

breathing

chest tightness

inhaler use

Belching associated

$\begin{array}{lcc}\text { cough } & 2(1.7) & - \\ \begin{array}{l}\text { wheeze } \\ \text { difficulty in } \\ \text { breathing } \\ \text { chest tightness }\end{array} & 2(1.7) & - \\ \text { inhaler use } & \mathbf{1 1 ( 9 . 2 )} & 1(1.2) \\ & 12(10) & 1(1.2) \\ & 3(2.5) & -\end{array}$

*All values are given as number (percentage).

in asthmatics with GORD symptom scores $>12.5$ compared to those with GORD symptom scores $<12.5$ (96\% versus $4 \%, P<0.05$, $\mathrm{z}$ test). The commonest symptom was reflux - associated difficulty in breathing. Table 5 shows the distribution of RARS.

\section{Association of asthma severity and asthma medication use with GORD symptom status}

One hundred and twenty asthmatics (59.4\%) had a GORD symptom score $>12.5$ and $36 \%$ of all asthmatics experienced one or more RARS. They differed significantly from those with GORD symptom scores $<12.5$ with respect to alcohol consumption, asthma severity and use of oral salbutamol but were comparable in age, gender, BMI and spirometry (Table 5). After adjusting for the five known confounding variables, multivariate analysis showed that asthma severity showed a significant dose-response association with reflux symptoms $(P$ value for trend $=0.007)$. When compared to patients with mild intermittent asthma, those with mild persistent asthma had a higher risk (OR 2.8 (95\% CI 1.1-7.0) and those with moderate or severe asthma had a much higher risk (OR 11.8 (95\% CI 1.5-92.9) of being GORD symptom positive (Additional file 1, Table S1).

\section{Discussion}

Estimates of the prevalence of GORD symptoms among adult asthmatics vary widely. The pooled sample-size weighted average prevalence of GORD symptoms in asthmatics reported in a review using data from seven crosssectional questionnaire-based surveys was $59.2 \%$ [1]. Other individual studies have reported prevalences of $45 \%$ [2], 69.2\% [6], 50\% [27], 49.4\% [28], 71\% [29], 52.2\% [30], and 51\% [31]. A more limited number of studies are available from South East Asia. A prevalence of 57\% in asthmatics compared to $34.1 \%$ in non-asthmatic controls has been reported from Thailand [2] and $74.8 \%$ from India [3]. Hence the prevalence of GORD symptoms seems to be similar within the South East Asian region and similar to that outside the region too. All these studies have been conducted in asthma clinics at secondary care hospitals in more urban settings [1]. As such our findings are directly comparable.

We defined GORD symptom status by use of a previously determined cut-off point on a GORD score constructed using a validated and reproducible questionnaire [26]. This composite score of GORD symptom frequency and severity has been demonstrated to have good correlation with 24 hour $\mathrm{pH}$ monitoring variables. We found that the mean composite GORD score was positive in $59.4 \%$ of asthmatics compared to $28.5 \%$ in non-asthmatics.

Typical symptoms such as heartburn and regurgitation are commoner than atypical symptoms in GORD patients $[32,33]$. From the present study, we found this to be true in our population of asthmatics. The third most frequent symptom was belching. We could not find any previous data on prevalence of belching or any other atypical symptom (chest pain or upper abdominal pain, abdominal distension, dysphagia) among asthmatics. 
The correlation in the literature between asthma severity and GORD is mixed. While Field et al. [20] reported that asthma symptom severity in the week preceding their interview did not correlate with either heartburn or regurgitation, the majority of studies have shown a positive correlation [4-6,33]. The severity of asthma in our patients (as defined by ATS criteria) showed a strong and dose-dependent association with GORD symptoms, an association that was independent of known confounders for GORD. The association between asthma severity and GORD symptoms has not been described previously in the South Asian region.

As this study was a cross-sectional, there is no indication of a temporal sequence or causal relationship between these two conditions. Whether the finding that more severe forms of asthma were associated with more reflux symptoms was due to reflux aggravating asthma or severe bronchospasm promoting reflux could not be determined.

In the present study, $36 \%$ of the asthmatics experienced reflux-associated respiratory symptoms (RARS) and these occurred more frequently in subjects who had positive GORD symptom scores. Other studies have investigated the association between typical GORD symptoms and respiratory symptoms. Field et al. reported a prevalence of $41.2 \%$. In this study 45 asthmatics out of 109 reported at least one RA0RS [20]. Another study reported that 'moderately bothersome' heartburn and acid regurgitation were significantly associated with asthma symptoms (odds ratio $=3.2 ; 95 \%$ confidence interval $=1.6-6.4)$, wheeze $(\mathrm{OR}=3.5$; $95 \%$ $\mathrm{CI}=1.7-7.2)$, and nocturnal cough $(\mathrm{OR}=4.3 ; 95 \% \mathrm{CI}=$ 2.1-8.7) independently of body mass index. This is the first report of an association of RARS with atypical symptoms of GORD.

Bronchodilator medication may predispose to gastrooesophageal reflux: theophylline has been shown to stimulate gastric acid secretion and lower LOS pressure, oral beta adrenergic agonists have been implicated in lowering the LOS pressure $[10,34]$, and oral corticosteroids have been shown to increase oesophageal acid contact times [11]. Debley et al. [35] demonstrated that GORD symptoms were associated with the use of asthma medication. A number of studies contradict these findings. Sontag et al. [36] showed that there was no significant difference in reflux patterns in asthmatics who were taking anti-asthmatic drugs versus those not taking them. Field et al. [20] noted that none of the asthma medications were associated with an increased likelihood of having symptoms of GORD. The NordTrondelag health survey showed that asthmatics had reflux symptoms to a $60 \%$ greater extent than non-asthmatics. However, asthma nor the use of asthma medication influenced the risk of GORD [37]. We found that
$64.4 \%$ of our asthmatics used one more oral drugs (beta $_{2}$ agonists, xanthines or steroids) for control of asthma. Asthmatics with positive GORD symptoms scores had significantly higher usage of oral salbutamol on univariate analysis. However adjustment for oral salbutamol use alone, and subsequently for all five asthma medications did not substantially alter the risk estimates for the different categories of asthma severity. Thus we have demonstrated that use of asthma medication, oral or otherwise, does not seem to influence the presence or absence of GORD. This has not been previously reported in an Asian population.

Several factors are known to contribute to both GORD and asthma. To reduce the risk of confounding factors we adjusted statistically for all plausible confounders. Alcohol consumption and smoking are known to be associated with GORD [38]. Recent reports indicate that in Sri Lanka, $41 \%$ of males and $3.4 \%$ of females are current smokers and $23 \%$ of men and $0.9 \%$ of women take alcohol at least monthly [39]. In our study, the percentage of current smokers (20\%) and drinkers (13.3\%) was lower than this. This could have been because these patients were hospital clinic attendees who are regularly exposed to health advice. The low prevalence may have resulted in our failing to show an influence of these factors on the presence of GORD symptoms in asthmatics, though it may also represent something specific about asthmatics and GORD and warrant further investigation. Increased body weight [40], increasing age and male sex [41] are also known to be associated with GORD. Our study design was such that asthmatics and controls were comparable in age and sex. An asthmatic had a higher risk of being GORD symptom positive compared to a non-asthmatic even after adjustment for known confounders. This indicates a lack of strong confounding by these factors, even though there was a significant difference in BMI, alcohol and tobacco consumption among the two groups. These findings are in agreement with previous studies [36].

\section{Conclusion}

In summary, use of an interviewer administered GORD questionnaire has shown a higher prevalence of GORD symptoms and RARS in a cohort of adult Sri Lankan asthmatics compared to non-asthmatics. The use of asthma medication does not influence the presence or absence of GORD though asthma severity shows a significant association. There is a significant burden of RARS morbidity in the region. We have now shown that the prevalence of RARS is associated not only with typical symptoms but also with atypical symptoms of GORD. This suggests that reflux associated respiratory symptoms may benefit from more rigorous investigation and, even when typical symptoms are absent, treatment of GORD may be indicated. 


\section{Additional material}

Additional file 1: Table S1 - Asthma severity, asthma medication use and GORD symptom status.

\section{Acknowledgements}

The authors acknowledge the financial support provided by research grant RG/2004/M/07 from the National Science Foundation of Sri Lanka.

\section{Author details}

'Department of Physiology, Faculty of Medicine, University of Kelaniya, Ragama, Sri Lanka. ${ }^{2}$ Department of Public Health, Faculty of Medicine, University of Kelaniya, Ragama, Sri Lanka. ${ }^{3}$ Department of Medicine, Faculty of Medicine, University of Kelaniya, Ragama, Sri Lanka. ${ }^{4}$ Department of Pharmacology, Faculty of Medicine, University of Kelaniya, Ragama, Sri Lanka.

\section{Authors' contributions}

All authors read and approved the final manuscript. All authors were involved in study conception, design, manuscript drafting and revision. In addition, LDA and AP were involved in statistical analysis. In addition, LDA was involved in data acquisition.

\section{Authors' information}

LDA: MBBS, Lecturer, Department of Physiology, Faculty of Medicine, University of Kelaniya, Ragama, Sri Lanka. AP : MBBS, MD, Professor of Public Health, Department of Public Health, Faculty of Medicine, University of Kelaniya, Ragama, Sri Lanka. HJDS : MBBS, MD, FRCP, FCCP, D Phil (Oxon), Senior Professor of Medicine, Department of Medicine, Faculty of Medicine, University of Kelaniya, Ragama, Sri Lanka. CDR : MBBS, BSc, MRCP, DTM\&H (Lond), Senior Lecturer in Pharmacology, Department of Pharmacology, Faculty of Medicine, University of Kelaniya, Ragama, Sri Lanka.

\section{Competing interests}

The authors declare that they have no competing interests.

Received: 24 February 2010 Accepted: 15 September 2010 Published: 15 September 2010

\section{References}

1. Havemann BD, Henderson CA, El-Serag HB: The association between gastro-oesophageal reflux disease and asthma: a systematic review. Gut 2007, 56:1654-64.

2. Chunlertrith K, Boonsawat W, Zaeoue U: Prevalence of gastro-oesophageal reflux symptoms in asthma patients at Srinagarind Hospital. J Med AssoC Thai 2005, 88:668-71.

3. Gopal B, Singhal P, Gaur SN: Gastro-oesophageal reflux disease in bronchial asthma and the response to omeprazole. Asian Pac J Allergy Immunol 2005, 23:29-34

4. Nakase H, Itani T, Mimura J, Kawasaki T, Komori H, Tomioka H, Chiba T: Relationship between asthma and gastro-oesophageal reflux: significance of endoscopic grade of reflux oesophagitis in adult asthmatics. J Gastroenterol Hepatol 1999, 14:715-22.

5. Gatto G, Peri V, Cuttitta G, Cibella F: Gastro-oesophageal reflux: prevalence in asthmatics in Italy. Dig Liver Dis 2000, 32:75.

6. Shimizu Y, Dobashi K, Kobayashi S, Ohki I, Tokushima M, Kusano M, Kawamura O, Shimoyama Y, Utsugi M, Mori M: High prevalence of gastrooesophageal reflux disease with minimal mucosal change in asthmatic patients. Tohoku J Exp Med 2006, 209:329-36.

7. Stein MR, Towner TG, Weber RW, Mansfield LE, Jacobson KW, McDonnell JT, Nelson HS: The effect of theophylline on the lower esophageal sphincter pressure. Ann Allergy 1980, 45:238-41.

8. Berquist WE, Rachelefsky GS, Kadden M, Siegel SC, Katz RM, Mickey MR, Ament ME: Effect of theophylline on gastro-oesophageal reflux in normal adults. J Allergy Clin Immunol 1981, 67:407-11.

9. Harding SM, Richter JE: The role of gastro-oesophageal reflux in chronic cough and asthma. Chest 1997, 111:1389-402
10. Crowell MD, Zayat EN, Lacy BE, Schettler-Duncan A, Liu MC: The effects of an inhaled beta (2)-adrenergic agonist on lower esophageal function: a dose-response study. Chest 2001, 120:1184-9.

11. Lazenby JP, Guzzo MR, Harding SM, Patterson PE, Johnson LF, Bradley LA: Oral corticosteroids increase esophageal acid contact times in patients with stable asthma. Chest 2002, 121:625-34.

12. Róka R, Rosztóczy A, Izbéki F, Taybani Z, Kiss I, Lonovics J, Wittmann T: Prevalence of respiratory symptoms and diseases associated with gastroesophageal reflux disease. Digestion 2005, 71:92-6, Epub 2005 Mar 16.

13. Foroutan HR, Ghafari M: Gastroesophageal reflux as cause of chronic respiratory symptoms. Indian J Pediatr 2002, 69:137-9.

14. Maher MM, Darwish AA: Study of respiratory disorders in endoscopically negative and positive gastroesophageal reflux disease. Saudi $J$ Gastroenterol 2010, 16:84-9.

15. Matsumoto $H$, Niimi A, Takemura M, Ueda T, Yamaguchi M, Matsuoka $H$ Jinnai M, Chin K, Mishima M: Prevalence and clinical manifestations of gastro-oesophageal reflux-associated chronic cough in the Japanese population. Cough 2007, 3:1-4.

16. Takenaka R, Matsuno O, Kitajima K, Ono E, Hiroshige S, Nishitake T, Miyazaki $E$, Kumamoto $T$ : The use of frequency scale for the symptoms of GORD in assessment of gastro-oesophageal reflex symptoms in asthma. Allergol Immunopathol (Madrid) 2010, 38(1):20-4, Epub 2010 Jan 25.

17. Kennedy $T M$, Jones $R H$, Hungin AP, O'Flanagan $H$, Kelly P: Irritable bowel syndrome, gastro-oesophageal reflux, and bronchial hyperresponsiveness in the general population. Gut 1998, 43(6):770-774

18. Gislason T, Janson C, Vermeire P, Plaschke P, Bjornsson E, Gislason D, Boman $G$ : Respiratory symptoms and nocturnal gastroesophageal reflux: a population-based study of young adults in three European countries. Chest 2002, 121(1):158-163.

19. Gunnbjornsdottir Ml, Omenaas E, Gislason T, Norrman E, Olin AC, Jogi R, Jensen EJ, Lindberg E, Bjornsson E, Franklin K, Janson C, Gulsvik A, Laerum B, Svanes C, Toren K, Tunsater A, Lillienberg L, Gislason D, Blondal T, Bjornsdottir US, Jorundsdottir KB, Talvik R, Forsberg B, Franklin $K$, Lundback B, Soderberg M, Ledin MC, Boman G, Norback D, Wieslander G, Spetz-Nystrom U, Cashelunge KS, Ryden E: Obesity and nocturnal gastrooesophageal reflux are related to onset of asthma and respiratory symptoms. Eur Respir J 2004, 24(1):116-121.

20. Field SK, Underwood M, Brant R, Cowie RL: Prevalence of gastrooesophageal reflux symptoms in asthma. Chest 1996, 109:316-22

21. Hancox RJ, Milne BJ, Poulton R, Taylor DR, Greene JM, McLachlan CR, Cowan JO, Flannery EM, Herbison GP, Sears MR: Sex Differences in the Relation between Body Mass Index and Asthma and Atopy in a Birth Cohort. Am J Respir Crit Care Med 2005, 171(5):440-445.

22. National Asthma Education and Prevention Program: Expert Panel Report 2: guidelines for the diagnosis and management of asthma. Washington DC: US Government Printing Office 1997.

23. Sistek D, Tschopp JM, Schindler C, Brutsche M, Ackermann-Liebrich U, Perruchoud AP, Leuenberger P: Clinical diagnosis of current asthma: predictive value of respiratory symptoms in the SAPALDIA study. Swiss Study on Air Pollution and Lung Diseases in Adults. Eur Respir J 2001, 17:214-9.

24. WHO bench aids for the diagnosis of intestinal parasites: WHO. Geneva 1994.

25. Udupihille M: Respiratory function tests: reference norms for the Sinhalese. Ceylon Med J 1995, 40:53-8.

26. Amarasiri LD, Pathmeswaran A, De Silva AP, Dassanayake AS, Ranasinha CD, De J: Comparison of a composite symptom score assessing both symptom frequency and severity with a score that assesses frequency alone: a preliminary study to develop a practical symptom score to detect gastro-oesophageal reflux disease in a resource-poor setting. Eur J Gastroenterol Hepatol 2010, 22(6):662-8.

27. Carmona-Sanchez R, Valdovinos-Diaz MA, Facha MT, Aguilar L, Cachafeiro M, Flores C, Solana S, Carillo G, Chapela R, Mejia M, PerezChavira R, Salas J: Gastro-oesophageal reflux in asthmatic patients: an incidence study and clinical correlation. Gac Med Mex 1999, 135(5):471-5.

28. Compte L, Garrigues V, Perpina M, Ponce J: Prevalence of gastrooesophageal reflux in asthma. J Asthma 2000, 37:175-82.

29. Sontag SJ, O'Connell S, Miller TQ, Bernsen M, Seidel J: Asthmatics have more nocturnal gasping and reflux symptoms than nonasthmatics, and they are related to bedtime eating. Am J Gastroenterol 2004, 99:789-96. 
30. Kiljander TO, Laitinen JO: The prevalence of gastro-oesophageal reflux disease in adult asthmatics. Chest 2004, 126:1490-4.

31. Gatto G, Peri V, Cuttitta G, Cibella F: Gastro-oesophageal reflux symptoms are more frequent in patients with severe asthma. Gastroenterol Int 2000, 13:139-42.

32. Klauser AG, Schindlbeck NE, Muller-Lissner SA: Symptoms in gastrooesophageal reflux disease. Lancet 1990, 335:205-8.

33. Cho YS, Choi MG, Jeong JJ, Chung WC, Lee IS, Kim SW, Han SW, Choi KY, Chung IS: Prevalence and clinical spectrum of gastro-oesophageal reflux: a population-based study in Asan-si, Korea. Am J Gastroenterol 2005, 100:747-53.

34. Lacy BE, Mathis C, DesBiens J, Liu MC: The effects of nebulized albuterol on esophageal function in asthmatic patients. Dig Dis Sci 2008, 53:2627-33.

35. Debley JS, Carter ER, Redding GJ: Prevalence and impact of gastrooesophageal reflux in adolescents with asthma: a population-based study. Paediatr Pulmonol 2006, 41:475-81.

36. Sontag SJ, O'Connell S, Khandelwal S, Miller T, Nemchausky B, Schnell TG, Serlovsky R: Most asthmatics have gastro-oesophageal reflux with or without bronchodilator therapy. Gastroenterology 1990, 99:613-20.

37. Nordenstedt $H$, Nilsson $M$, Johansson $S$, Wallander MA, Johnsen $R_{\text {, }}$ Hveem K, Lagergren J: The relation between gastro-oesophageal reflux and respiratory symptoms in a population-based study: the NordTrondelag health survey. Chest 2006, 129:1051-6.

38. Dent J, Brun J, Fendrick AM, Fennerty MB, Jannssens J, Kahrilas PJ, Lauritsen K, Reynolds JC, Shaw M, Talley NJ, on behalf of the Genval Workshop Group: An evidence-based appraisal of reflux disease management - the Genval Workshop report. Gut 1999, 44:S1-S16.

39. Perera B, Fonseka P, Ekanayake R, Lelwala E: Smoking in adults in Sri Lanka: prevalence and attitudes. Asia Pac J Public Health 2005, 17:40-5.

40. Cremonini F, Locke GR, Schleck CD, Zinsmeister AR, Talley NJ: Relationship between upper gastrointestinal symptoms and changes in body weight in a population-based cohort. Neurogastroenterol Motil 2006, 18:987-94.

41. Ter RB, Johnston BT, Castell DO: Influence of age and gender on gastrooesophageal reflux in symptomatic patients. Dis Esophagus 1998, 11:106-8.

\section{Pre-publication history}

The pre-publication history for this paper can be accessed here: http://www.biomedcentral.com/1471-2466/10/49/prepub

doi:10.1186/1471-2466-10-49

Cite this article as: Amarasiri et al.: Prevalence of gastro-oesophageal reflux disease symptoms and reflux-associated respiratory symptoms in asthma. BMC Pulmonary Medicine 2010 10:49.

\section{Submit your next manuscript to BioMed Central and take full advantage of:}

- Convenient online submission

- Thorough peer review

- No space constraints or color figure charges

- Immediate publication on acceptance

- Inclusion in PubMed, CAS, Scopus and Google Scholar

- Research which is freely available for redistribution

Submit your manuscript at www.biomedcentral.com/submit
Ciomed Central 